\title{
5
}

\section{Public Facebook Groups for Political Activism}

\author{
Madelyn Rose Sanfilippo and Katherine J. Strandburg ${ }^{2}$
}

\subsection{INTRODUCTION}

The rise of social media has raised questions about the vitality of privacy values and concerns about threats to privacy (Marwick and boyd, 2014). As online communities have flourished, debate over appropriate information flows among users, as well as to platforms, service providers, and surveillance networks, has grown (Ellison et al., 2011; Marwick and boyd, 2014). Facebook has received considerable scholarly attention (e.g. Acquisti and Gross, 2006; Hargittai, 2010) in this debate. Social media use has become pervasive not only in economic and social interactions (Kaplan and Hainlein, 2010) but also in politics and political organizing (Gonzalez-Bailon and Wang, 2016; Nam, 2012). The convergence of politics with social media use amplifies the privacy concerns traditionally associated with political organizing (Breuer, 2016; Nam, 2012), particularly when marginalized groups and minority politics are involved (Stacheli, 1996).

Despite the importance of these issues, there has been little empirical exploration of how privacy governs political activism and organizing in online environments. This project explores how privacy concerns shape political organizing on Facebook, through detailed case studies of how groups associated with March for Science, Day Without Immigrants ("DWI"), and Women's March govern information flows. Each of these groups emerged from distributed grassroots efforts, gaining critical

We thank participants at PLSC, the 2nd Annual CI Symposium, and the Workshop on the Growing Influence of Social Media in Global Politics and Society for their valuable feedback. We also thank NYU's Information Law Institute, which supported Madelyn as a fellow while this research was conducted, and the Microsoft Corporation for its generous support of the ILI Fellows program. This chapter draws, in part, on research published: Sanfilippo, Madelyn Rose, and Katherine J. Strandburg. "Privacy governing knowledge in public Facebook groups for political activism." Information, Communication E Society (2019): 1-18.

1 Assistant Professor, School of Information Sciences, University of Illinois at Urbana-Champaign; Affiliate Scholar, The Vincent and Elinor Ostrom Workshop in Political Theory and Policy Analysis, Indiana University, Bloomington. Ph.D., Indiana University, Bloomington; M.I.S., Indiana University, Bloomington; B.S., University of Wisconsin-Madison.

$=$ Katherine J. Strandburg is the Alfred Engelberg Professor of Law and Director of the Information Law Institute at New York University. 
visibility and participation because of their use of social media both to organize demonstrations and events and to share political knowledge ideas. This comparative case study employs an empirical framework that we developed in earlier work (e.g. Sanfilippo, Frischmann, and Strandburg, 2018), in which we synthesized contextual integrity analysis (Nissenbaum, 2009) with the Governing Knowledge Commons (GKC) framework (e.g. Madison, Frischmann, and Strandburg, 2014) for institutional analysis of commons governance of knowledge (e.g. Ostrom, 2011).

The specific activist movements we have studied - the March for Science, the DWI, and the Women's March - are recent examples through which we can explore how privacy governs both the organization of activism, particularly in an age of social media and surveillance, and the sharing of knowledge in public Facebook groups. All three movements grew quickly in scale and structure following the 2016 presidential election, leading up to demonstrations in early 2017 through extensive use of social media and under the attention of traditional media.

The January 21, 2017, Women's March on Washington, along with the 672 other satellite marches that took place on all seven continents, drew between three and five million people (e.g. Boothroyd et al., 2017; Wallace and Parlapiano, 2017). While the Women's March focused on women's issues, it became a venue for expressing solidarity and concern relative to many other human rights issues (Boothroyd et al., 2017; Fisher, Dow, and Ray, 2017). This movement originated with a single individual on Facebook proposing a march on Washington, DC, and eventually evolved into a sustained organization advocating and informing regarding gender and equality issues in a historical moment when opposition to misogyny and sexual violence is historically prevalent (Fisher, Dow, and Ray, 2017; Moss and Madrell, 2017). While historically, many movements have petered out after largescale demonstrations, the Women's March organization has continued to organize events and information campaigns, including the Women's Convention and a second annual Women's March in 2018. It has also grown in public support, as the \#MeToo movement has intersected with it. The national movement also has been criticized, however, by some who see it as less inclusive of women of color than some of the local efforts have been (Boothroyd et al., 2017; Rose-Redwood and RoseRedwood, 2017).

The April 22, 2017, March for Science drew on many existing advocacy networks, piggy-backing on and transforming an annual Earth Day observance in response to a post-truth era in which the legitimacy of science and objectivity are questioned; 1,070,000 people are estimated to have attended worldwide (Milman, 2017). While movement was not initiated on Facebook, it employed Facebook to muster pro-science support and respond to perceptions of manipulation of scientific information and "fake news" (e.g. Reardon et al., 2017). Like the Women's March movement, the March for Science movement has maintained visibility after the March and continues to respond to anti-science, anti-fact rhetoric in politics, media, and social networks. 
Unlike the Women's March, however, it did not coalesce into a formal organization.

The February 16, 2017, DWI was different from the other two movements we studied in that it did not focus on a large-scale march in Washington, DC. DWI was primarily intended to illustrate the importance of immigrants to the economy, as well as to advocate for immigration reform. It also expressed opposition to the proposed border wall and to racial profiling (Robbins \& Correall, 2017). Demonstrations were held in thirty cities across the United States, while individuals who did not march expressed solidarity through other forms of protest and boycotts. Some restaurants and businesses also closed to express their support (Stein, 2017). The DWI movement was organized through more distributed networks of immigrants and their supporters, working in various ways to advocate and make their influence felt through a day in which they did not participate in the economy (e.g. Blitzer, 2017). Facebook's network structure was employed by the movement to allow groups to connect, learn from one another, and share information (e.g. Hamann and Morganson, 2017).

These three cases are particularly fruitful to compare because they were similar in many respects, but differed in significant ways relevant to privacy. All three movements emerged in response to the rhetoric and political positions, or actions, of President Donald Trump and were active during the same period. Yet the historical legacy of each movement also shaped each response in a distinctive way. The Day with Immigrants and Women's March movements stemmed from historically entrenched marginalization and inequalities based on ethnicity and gender, respectively - and from a concern that society was beginning to move backward on these issues. The March for Science, on the other hand, was a response to a relatively more recent and emerging concern about disintegrating societal respect for and trust in science.

Social media also played an enormous role in facilitating interactions between organizers and publicizing each of these movements and their events. These cases, addressing distinct issues, while operating in similar contexts and on the same timescales, thus allow for the exploration of privacy, as it plays out through governance of personal information flows, for both political organizing and Facebook sub-communities. Privacy practices and concerns differed between the cases, depending on factors such as the nature of the group, the political issues it confronts, and its relationships to other organizations or movements.

In order to better understand what these cases can reveal about privacy as governance of personal information flow, in the context of political activism and for organizations coordinating through Facebook, we employ the Governing Knowledge Commons framework, which we have recently adapted for the study of privacy (Sanfilippo, Frischmann, and Strandburg, 2018). 


\subsection{RESEARCH DESIGN}

This case study focuses on six March for Science groups (Austin, TX; New Jersey; New York, NY; Princeton, NJ; Seattle, WA; and Washington, DC), seven Women's March groups (Ann Arbor, MI; Atlanta, GA; Global, which represented all international events; Madison, WI; New York, NY; Princeton NJ; Washington, DC), and eight DWI groups (Baltimore, MD; Elkhart, IN; Greenville, NC; Nashville, TN; Students; VA; WA; Washington, DC). In addition to analysis of 4,352 posts from the DWI, 294,201 from the March for Science, and 196,358 from the Women's March, we conducted interviews with decision-makers from these twenty-one groups, structured by the questions within the GKC framework, and distributed surveys to their members. Our textual analysis placed particular emphasis on public Facebook discussions of privacy, information flows, and institutional legitimacy and development. We also used network analysis to interrogate the relationships between national and satellite groups within each movement, between groups associated with different movements, and between each movement and external organization.

Additional details about our methods, and these cases, can be found in two companion journal articles, analyzing aspects of participatory privacy (Sanfilippo and Strandburg under review) and how privacy in knowledge resources governs online political movements (Sanfilippo and Strandburg, 2019).

\subsection{BACKGROUND ENVIRONMENTS FOR THE CASE STUDIES}

\subsubsection{Day Without Immigrants}

Participants, including members and followers, and non-member discussants within various DWI Facebook groups provided a rich depiction of the background context in which they were organizing, emphasizing how both supportive participants and their opposition saw the movement as fitting into a larger narrative of social and political dimensions, including recognition of how the movement related to the 2016 presidential election. Discussion, and embedded arguments, focused on what was perceived to have changed under President Trump; while many recognized the historical path, "The immigration system is broken and for most of the Central America and South America countries the only way to come here is a stupid lottery created 50 years ago," others recognized the rhetorical changes in the national dialogue as leading to something different, for example contesting that "Donald Trump was talking about ... CRIMINAL illegal immigrants." Action was perceived to be required in order to fight against both the historical trend and the current threats. As one organizer explained, "Gracias. Injustice under Trump is not only seen more, but more severe. It is an important time to act and I need to be a part, for myself and for others." 
The DWI movement thus emerged from a background environment in which many supporters, as potential participants, had serious concerns about potentially dire consequences for themselves or their family members if they were identified in a public forum. President Trump's anti-immigrant campaign rhetoric and promises heightened fears of discrimination and racial violence for many immigrants, especially Latinos, whether documented or undocumented, as well as fears of mass deportation for undocumented immigrants, including hundreds of thousands of DACA recipients and millions of DREAMERS (Kocher, 2017).

One consequence of the heightened vulnerability of undocumented immigrants was that many of their documented friends and relatives felt a similarly heightened responsibility, despite their own fears of discrimination and retaliation, to take up visible roles in the movement, since such roles were perceived as too dangerous for the undocumented.

\subsubsection{Women's March}

The Women's March was galvanized by President Trump's election in a contest that most expected Hillary Clinton, the nation's first female presidential candidate, to win. Many women experienced Trump's win over Clinton, despite her substantial expertise and government experience and his complete lack of either, as a wake-up call. Women's outrage over Trump's election was heightened by his record of disrespectful behavior and comments, including those recorded on the infamous Access Hollywood tape, and the numerous sexual harassment and assault allegations that emerged shortly before the election.

The background environment included the long-standing movement for women's rights. Equality and respect, as both objectives and core values of the historic women's movement, shaped Women's March institutions in fundamental ways. Specific values emphasized centered on inclusion and privacy, as concerns about safety, in the wake of sexual harassment and assault allegations against President Trump and recent history of \#gamergate, made concerns about targeting individuals serious (Moss and Madrell, 2017).

\subsubsection{March for Science}

Unlike the other two movements, the March for Science did not grow out of a historical political movement responding to discrimination or hostility. Rather, it was a response to a fear that science was in danger of losing the nearly universal status and acceptance that it has enjoyed in modern times. An anti-science strain had been emerging in US politics for a few years, particularly within the Republican Party, particularly in relation to issues such as energy and climate change (Selepak, 2018). The 2016 campaign, culminating in President Trump's election, crystallized and heightened scientists' fears that facts, objectivity, and scientific evidence were 
being supplanted in public discourse and decision-making by reliance on experience, personalization of information in favor of beliefs over facts, and conspiracy theories. These threats to scientific values were accompanied by more practical concerns about the possibilities of funding cuts, disruption of accepted scientific standards for peer review and allocation of funding, and corruption of the output of government-supported scientific endeavors.

Reflecting its emergence out of concerns for loss of historical status, the March for Science drew from the outset directly on the support and resources of large and established scientific professional organizations. In this respect, it differed notably from both the Women's March and DWI. In deciding whether to become involved in the political arena by organizing a March for Science, scientific organizations and individual participants confronted the question of whether participating, as scientists, in a movement that responded directly to the election of a particular president would violate scientific norms of objectivity that had ordinarily been understood to include political nonpartisanship. Some members of the scientific community viewed participation as a means of opposing an already dangerous politicization of science, while others feared that employing the tools of political advocacy on behalf of science would contribute to its further politicization.

\section{$5 \cdot 4$ ATTRIBUTES}

\subsubsection{Community Members}

\subsubsection{Membership}

In the most expansive sense, community members could include everyone who supported the movement in any way at all, including expressing agreement with its aims, providing financial support, attending a national or satellite march, RSVPing on EventBrite, joining an associated Facebook group, attending offline events or meetings, or serving as an organizer for one of the events. Beyond even the most inclusive definition of community "members" taking part in the movement, each of the movements we studied had the potential - and the goal - to impact outsiders. In a broad sense, each of these movements had the potential to affect society at large. More specifically, potentially impacted outsiders encompassed all women, immigrants, and scientists who did not participate, including some who remained outside because they were concerned about the consequences of participation.

Our discussion of "members" of a particular group or march will ordinarily refer to individuals who joined one of the Facebook groups studied. Membership in these public Facebook groups was not representative of all members or supporters. This is most emphatically the case for the DWI movement because privacy concerns were a serious barrier to publicly affiliating with the movement on Facebook. To give us further insights into community membership, we have supplemented the detailed 
TABLE 5.1 Attendance versus expectations

\begin{tabular}{lccc}
\hline \hline Movement & Day Without Immigrants & March for Science & Women's March \\
\hline Attendance & 3940 & 206000 & 1578500 \\
EventBrite RSVPs & 1278 & 172000 & 798800 \\
Facebook RSVPs & 621 & 61500 & 402026 \\
\hline \hline
\end{tabular}

picture available from our main sources with estimates of march attendance and numbers of EventBrite RSVPs for our case study groups, as well as data about all organizations affiliated with the national groups and geographic co-location data for national and all satellite marches.

Table 5.1 shows the numerical relationships between estimated attendance, EventBrite RSVPs, and Facebook group members for the groups included in our study. For each movement, we compare projected attendance based on different platforms with estimated aggregate attendance at the 2017, or first wave of, national and satellite marches. (We do not consider follow-up marches in this study.)

For all three movements, the number of march attendees was larger than the number of EventBrite RSVPs, which was yet larger than the expected numbers based on responses within the associated Facebook groups. As a fraction of attendees, DWI supporters were the least likely to register in advance, either by RSVPing through EventBrite or by participating in a Facebook group, including by formally joining or by responding to event invitations. Though there are various possible explanations for this trend, it seems plausible that this failure to register in advance reflects greater concern within DWI about leaving persistent, personally identified, public trails of their involvement in the movement.

The preference for EventBrite over Facebook across all three movements also reflects privacy concerns, since EventBrite RSVPs are not public, do not link to vast amounts of personal information, and can be made effectively anonymous. As one key organizer from the New York City Women's March explained:

We needed to have a way of developing unique registrations, but at the same time, we're dealing with people involved in activism, and we want people to know that their information is secure, right? So, that's one reason we started using EventBrite, just to get the numbers. Now, the thing is, you don't have to put your real name in there. You don't even have to put in a real email address. You can put in an address, you know, that's a temporary one. People make those all the time ... but, you know, it was a way for us to keep track.

Participation in all three movements was open to the public at nearly every level of involvement. Anyone could (and was encouraged to) attend the marches. All three national marches, as well as the satellite groups that we studied, maintained public 
Facebook groups. Anyone could join these groups, yet membership was not required to participate in public discussions and there were few limits placed on discussion contributions. Though membership in the public Facebook groups associated with the various national and satellite marches was generally open to anyone, privacy concerns created significant barriers to membership in the Facebook groups associated with DWI, as discussed in greater detail later.

The openness of these public Facebook groups meant that not only supporters but also individuals who were hostile to a group's goals and objectives could join. This openness to dissenters sometimes resulted in contentious - or even troll-like exchanges. Maintaining this openness, despite the dissension it invited, was considered important by many groups not only as a means to inform and engage the broader public but also as a way to signal willingness to engage in reasonable debate. In particular, discussions within the Facebook groups of various DWI movement groups emphasized the hope that openness would help to legitimize the planned marches in the eyes of the public.

\subsubsection{Community Demographics}

The demographic makeup of each movement largely aligned with objectives. Thus, Women's March organizers and other participants were overwhelmingly female and, as some impacted outsiders critiqued, overwhelmingly white (Fisher, Dow, and Ray, 2017; Rose-Redwood and Rose-Redwood, 2017). Many DWI group demographics roughly reflected the demographics of the undocumented population, though organizers specifically were more often those with more legal security, such as DACA recipients, Green Card holders, and legally documented relatives. Furthermore, a minority of satellite groups within this movement more broadly reflected the demographics of recent immigrants, rather than reflecting the undocumented population. Moreover, participants in both of these movements included family members and other supporters who did not fit the mold.

The March for Science was supported by numerous scientific organizations and many participants were research scientists and medical professionals. However, participants, including many organizers, also included many K-12 educators, students, university administrators, and corporate R\&D staff. Families turned out for the affiliated Earth Day events, capitalizing on the openness of their designs and appealing to the assertions that trust in the objectivity of science should be learned early and believed pervasively. Moreover, while STEM fields have continuing, and historical, gender diversity problems, various March for Science groups were not only more gender-balanced but organized by women.

Moreover, some satellite marches, such as the Atlanta March for Social Justice and Women, intentionally defined themselves differently and in more inclusive ways, to better reflect the diversity of stakeholders in their local communities. As one co-organizer of the Atlanta event explained: 
We are a non-profit organization and we organized the March for Social Justice, which coincided with the Women's March all over, to represent all marginalized communities and to stand up for our rights and opportunities in the face of opposition. We wanted to stand together, for women, for our LGBTQIA friends, for people of color, for my fellow Muslim Americans and all religions, for ... autonomy over our bodies and safety, for voting rights, for things we deserve and expect, but are held back and repressed, for victims of sexual violence who aren't believed. For immigrants, of all statuses ... I am involved because I want to stand up for myself and my community, not just by marching, but by making the demonstration and ongoing activism as impactful as possible.

In contrast to efforts by this satellite march to be inclusive in organization and participation, DWI movement groups were almost intentionally obfuscating in their design; many of these groups were composed, at least with respect to public affiliation, primarily of the friends, documented significant others, and children of undocumented immigrants, rather than by undocumented individuals - the most seriously impacted stakeholders. The absence of these individuals from publicly acknowledged membership did not necessarily preclude their participation or the reflection of their preferences, but rather mediated it for safety. As one organizer explained:

My mom and my aunt took me to a protest when I was a kid and from then on, I knew this was important and I wanted to help. I was born here, but people in my family are undocumented. ... How can you just watch bias or discrimination and not do something, you know? So in this case, my aunt had been discussing this with other activists around immigration, but wasn't going to go on social media, but I could and did, and then it could get around to lots of other people.

This individual was thus simultaneously in the roles of organizer-group member and proxy for family members, in order to protect the privacy of those family members.

\subsubsection{Outside Groups}

In addition to their individual members and organizers, these movements were supported in various ways and to greater and lesser degrees by pre-existing organizations. The Women's March and March for Science each were affiliated with a large number of outside organizations, including thirty-nine organizations that interacted with both. The DWI movement, by contrast, had very few connections with outside organizations. Only one organization, the AFL-CIO, supports both DWI and the Women's March. DWI shares no external affiliates with the March for Science.

These external affiliations reflect the dramatically different roles that outside organizations played in different movements. At one extreme, many March for Science events were not only supported by but also directly organized by preexisting organizations - professional, academic, and advocacy-oriented. At the 
other extreme, the DWI movement intentionally eschewed most public affiliations with advocacy groups, even when receiving other kinds of support from such groups. The Women's March was positioned at a relative middle ground with respect to the influence of outside organizations. Interestingly, the Women's March also institutionalized itself, formalizing an organization that was much more lasting and stronger than either of the other movements.

\subsubsection{Resources}

Across all three movements, information resources were developed, aggregated, and shared to inform members, other participants, impacted individuals, and the general public about the movements' objectives and events, as well as to share human interest stories and news coverage of their activities, and provide information resources for impacted populations. By using public Facebook pages, groups from all three movements made these shared information resources open resources, leveraging the visibility Facebook, and other social media platforms, provided to cultivate their own knowledge resources for use by affected individuals beyond participating stakeholders.

Prioritization of choice and opportunity shaped not only each group's online information sharing practices, as described with respect to the mailing lists and organizational partnerships, but also the information resources constructed (Kitch, 2018). Facebook and social media were most visibly central to the Women's March, perhaps partly because of the role social media played in the group's origins, but also because social media were seen as legitimate forums for personal information and sharing by participants in this movement. Facebook was not, however, considered to be perfect for this or any movement. Other tools and channels, such as EventBrite, were deemed necessary both to allow organizers to better anticipate numbers of demonstrators and to ensure that feminists and supporters who did not participate in Facebook could be adequately up to date on important information.

Facebook also had a significant impact on these activist movements because of the way it affected dialogue, by increasing disinhibition and opening groups to criticism, rather than simply insulating them. Interestingly, the smaller the group, the less it appears to attract critical posts, even when a small satellite was organized in a place where one would expect little ideological alignment between the movement and the populace at large. This was especially the case for small DWI groups, but also seemed to be true for smaller Women's March satellites. Furthermore, some groups defused opposition by describing their membership in more socially acceptable terms; for example, groups organized by students and "DREAMERS" were perceived to be "sort of good that kids care about STEM" and "the kind of immigrants we want" (Facebook posts). "Asian and well-educated" immigration groups were also complimented, even by individuals who publicly stated their opposition to 
the DWI movement overall. In contrast, plenty of opposition was expressed relative to "Mexican, undocumented" groups. Obvious stereotypes played out in this environment, particularly relative to the perceived legitimacy of action arenas and resources, as individuals were open about their fears and prejudices in the mediated environment. In the words of one Facebook post, "Like you would even say that if this wasn't fb!"

In the course of their activities, these groups handled large amounts of personal information. Some of this information was in the obvious form of contact information for members of the Facebook groups and those who RSVP'd using their real identities on EventBrite. But other personal information emerged less obviously, from discussions in the Facebook groups as individuals debated issues and told personal stories, or in photos taken at demonstrations. All of these forms of personal information were absolutely central resources for these movements, enabling coordination, publicity, public engagement, and more for these groups.

\subsubsection{Contact Information}

Norms about how to generate and secure RSVP lists and contact information reflected at least a partial consensus across movements about how to handle this form of personal information in online political organizing. Groups in all three movements used both public Facebook pages and EventBrite RSVPs, to developing lists of those who intended to participate in the marches. EventBrite was considered to be more accurate than Facebook, as well as more private, though neither provided complete lists of attendees. As an organizer of the NYC Women's March explained, "I really recommend that to people if they're doing their own event. Have multiple channels, even if they're different, have multiple channels. Because we had people registered through Facebook, and I think it was only 50,000. [laughter] And over 200,000 in EventBrite alone."

Yet while their basic approaches to gathering information resources were superficially similar, the movements diverged in important ways in their assessments of appropriate flow of these information resources. The DWI movement eschewed affiliations with outside groups in order to create a barrier to information flow about the identities of those who were involved with the movement. The Women's March was affiliated with a large number of outside organizations, but groups often did not share member lists or contact information with those organizations.

The New York City Women's March group, for example, did not share contact information or other personally identifiable information about members, attendees, or subscribers with outside organizations, no matter how closely interests and objectives overlapped. Nor did it accept similar information from such organizations. Instead of sharing contact information, the new group pursued its shared objectives with outside affiliates by publicizing events and information relating to its partner organizations, so that the group's members could find out about other 
organizations and events reflecting their interests. They went so far as to delete the contact information and email list it had generated for the 2017 march, so as to prevent anyone under any circumstances from obtaining that information. As one key organizer explained,

we needed to have a way of developing unique registrations, but at the same time, we're dealing with people involved in activism, and we want people to know that their information is secure, right? So, that's one reason we started using EventBrite, just to get the numbers. Now, the thing is, you don't have to put your real name in there. You don't even have to put in a real email address. You can put in an address, you know, that's a temporary one. People make those all the time ... but, you know, it was a way for us to keep track. We were still, you know, knowing some people would put their real name in there, we wanted to establish a list for when the march was over. We had an opt-in process, after the march, for people wanted to continue to receive email from us and then we destroyed the original database.

To work around the difficulties imposed by the decision to delete the lists, subscribers to the list had to opt-in to be contacted for future events.

Both of these approaches were in stark contrast to the easy exchange of contact information that occurred between science and technology organizations and March for Science groups. For these groups, the appropriateness of sharing contact information with affiliate organizations was established by the identification of these affiliates as reputable professional organizations. One Women's March organizer, who was also involved, to a lesser degree, in organizing a March for Science satellite march, identified a source of this difference in perspective between the March for Science and the other movements, stating “it's an issue of trust in the powers that be. People who have been historically discriminated against don't trust the status quo in the same way that scientists who are respected professionals might. It's completely different."

\subsubsection{Stories, Narratives, and Other Forms of Personal Information}

All of these movements also accumulated personal information in the form of stories and other personal details and each dealt with such information differently. The desire to use personal stories as a way of appealing to the public was common to all three movements, but levels of comfort in linking those humanizing stories to real identities differed greatly. The March for Science encouraged publicly identifiable scientists to share their personal stories and commitment to the movement. One March for Science organizer explained that "it was best when we could get famous faculty to buy-in and talk, not just demonstrations and things for kids, but in a way that was more political, because it got attention and was ... I guess, more credible." However, very real fears about employability were expressed by junior scientists, 
making privacy a core organizing value. In contrast to leveraging privacy by obscurity, as within the Women's March, or privacy by proxy, as within the DWI movement, participants within the March for Science used established figures and institutions as shields, providing privacy to graduate students, for example, who served in key organizational roles.

DWI groups, at the other end of the spectrum, were more uniformly averse to sharing personal stories in ways that identified the status of particular individuals. Posts on public Facebook groups devoted to the movement illustrate direct admonitions against individuals who shared the stories of their friends, as well as metadata revealing deleted posts preceding these discussions as evidence of moderation to control information flows regarding immigration status. Furthermore, comments posted provide general warnings to be careful with information about immigration statuses, along with extensive discussions revealing support for this specific aversion to sharing among discussants and members of these groups.

Facebook discussions and interviews, relative to the DWI movement, included many expressions of fear and concern about what ICE and law enforcement might do with the personal information of any undocumented members who were publicly associated with the movement. These fears strongly affected the willingness of DWI supporters to formally affiliate with the movement on Facebook, as participants in the groups, or even to maintain Facebook accounts. As a result, while Facebook was often used to publicize demonstrations and share resources, other, less permanent and public tools, such as encrypted messaging apps promoted by Cosecha or Snapchat, were employed for organizing and connecting undocumented individuals to the movement. Even Snapchat was often avoided, because of its relationship to Facebook.

Women's March groups varied in their approaches to sharing personal stories. Rather than avoiding documentation of personal information or identities, as with immigrants and their advocates, the Women's March sought safety in numbers and privacy through obscurity, tightly controlling images documenting the events and contact lists, as much as possible. Because the \#MeToo movement unfolded during the course of interviews for this study, a number of interviewees mentioned the impact that the movement was having on women's willingness to share their stories, yet worried about the potential consequences of being able to connect stories shared online with real world identities. For example, one Women's March interviewee noted that "we didn't really have strict rules about people disclosing personal information, sensitive stories or anything, but I'm getting worried about it, still moderating the group, with \#MeToo, because I'll feel responsible when some weirdo decides to target someone because of what they've posted in our group, like the physical threat is real." These comments evoke similar concerns to those expressed by members of the DWI movement relative to threats of deportation or problems from legal authorities that might arise if the immigration status of anyone associated with the movement could be gleaned from its Facebook groups. 
Most groups addressed concerns about inappropriate personal information flows primarily using rules and norms about sharing using the group's Facebook pages and other, now traditional, communications technologies, such as email. Additionally, however, interviewees from a number of DWI groups reported receiving lessons from organizations such as Cosecha, to help them understand how to appropriately use privacy-enhancing technologies, such as encrypted messaging or Slack channels, rather than more visible platforms like public Facebook groups.

\subsubsection{Photos and Other Visual Resources}

One arena of particular concern related to the identifiability of those who attended events from photographs taken or posted that captured participation in political demonstrations. While most groups, across all three movements, gladly accepted photographs of themselves that individuals shared with the group, some struggled with how to manage photographs of others that had been taken or shared without their consent. As one March for Science organizer explained:

You sort of expect to be seen when you go to a protest in a public place, but there is a sense of safety in a crowd. You're not the only one, but you can be singled out in a picture, and that becomes more complicated ... especially when it's suddenly online forever. We get that this is a real career risk.

In addition to privacy concerns, sharing of photographs and other information resources sometimes raised questions about intellectual property and ownership, as one organizer of a Women's March satellite explained:

You've got volunteers creating graphics for logos and banners and things ... teeshirts .... And those people aren't savvy enough to negotiate the rights to that stuff, so then you have weird rights issues that come up. Umm ... there's navigating that whole nightmare, then, umm ... and something we're still navigating, is that we had a whole group of photographers taking pictures. Umm ... and we were lucky, in that our lead, the leader of the photographers got written agreement with the group of photographers that we had, to get the rights for use of those images collected.

Groups also worried about how to ensure that photographs of their events and marches were preserved. Many followed the early example provided by the NYC Women's March, in securing the photos on their own machines or servers, rather than entrusting them to social media alone. The NYC Women's March began this practice in hopes of developing an archive of such images.

\subsubsection{Information Quality and Fake News}

Organizers also worried about ensuring the reliability and quality of the information that were shared on their groups' Facebook pages. As one March for Science 
organizer explained, "It's not unfounded to be concerned that facts and science are undermined anytime any influential person says, 'Oh, fake news,' it's actually happening." Many organizers expressed concern about establishing trust in the resources they developed and shared on behalf of their groups. To address these concerns, groups not only doubled checked FAQs, to ensure that the correct and most up to date information was being shared, but also made efforts to provide quality control regarding news stories and links shared by participants within Facebook groups.

These information quality concerns extended in some ways to personal information. Organizers were concerned not only about the obvious things, such as obtaining correct contact information and ascertaining RSVP quality, but also about ensuring that lies weren't being spread through their platforms via personal stories. As one DWI organizer explained:

Fake information is a problem, but honestly ... if people take 5, 10 minutes of time to really look into a story or recheck the facts ... it's not any longer than a few google clicks away to verify. There have been ... I have seen some fake news about some woman who got deported, like, making fun of her ... it turned out it was fake news. What ended up happening? Nothing really happened. It's a thing, it looks sensational, but it's usually obvious if it's really if you look up the story and only find one fringe article ... I kind of double check all my stuff before I post it . . . you've got to be careful, that's the problem with ... but a hoax will die out or blow up really quickly ... you can update or repost to keep things prominent, to folks everywhere, all the time.

Many groups, across movements, documented their processes of vetting stories, including news stories, that were shared within the group's Facebook discussions. For example, a DWI post reflected a norm of vetting through careful reading, "Thanks for sharing this. I will wait to comment until I have a chance to read all of this!" while a March for Science post reflected a norm of confirming sources, "[T]his looks great, but we will get more sources before we add it."

Organizers across all three movements emphasized that it often took only a little work to verify information veracity.

\section{$5 \cdot 4 \cdot 3$ Goals and Objectives}

The objectives underlying the movements are tied strongly to the exogenous influences associated with their formation, as well as to historical interests shaping their contexts. These objectives reflect common values such as equality, transparency, truth, and fairness, as well as interests unique to each group. The general goal of each of these three movements, though details are specific to each movement and group, is, in part, to resist Trump's agenda in favor of more progressive policies and changes. All groups also shared the objective of informing the public about their focal issues. Groups uniformly placed high value on knowledge production and, as 
described in the previous section, on maintaining the veracity and quality of the group's information resources.

All of the movements were confronted by entrenched political opposition. Sometimes there were subareas within a movement's objectives where consensus with at least some opposition actors could be reached. For example, children of immigrants were viewed relatively favorably and DACA was a more acceptable issue to address than amnesty. As one Facebook user stated "Yes the people who have crossed the border without a choice are the children they bring, are they criminals too?" Supporters and many who originally identified as the opposition agreed that children had no choice and thus this was seen to be a legitimate objective.

Sometimes, however, opposition led to counter-movements, or even harassment and threats. While some Women's Marches saw anti-abortion, or more specifically, anti-Planned Parenthood, counter-protesters, DWI groups experienced the most visible detractors, with bigoted and hateful language directed toward them, as well as threats made toward exposing individuals to scrutiny over their own statuses. Even the well-sourced resources and campaigns developed by the March for Science was subjected to the same hostility to objectivity that the movement emerged to address. When intelligent public information campaigns were disseminated, comments were posted decrying them as propaganda; for example "Drinking the left wing koolaid made by the C.linton N.ews N.etwork."

The national March for Science group developed and disseminated a relatively clear set of top-down objectives, while the Women's March and DWI movements presented patchworks of objectives even at the national level. Regardless of the degree of consistency at the national level, satellite groups unavoidably augmented and modified national objectives to reflect local contexts.

Many March for Science satellite groups were defined more specifically by goals and objectives determined in the local context. For example, the backgrounds of the individuals determining the agenda and specifying the goals varied from group to group. For example, one group might be organized by the American Association for the Advancement of Science (AAAS) members, while another was organized by high school science teachers. Differences between groups within the March for Science movement could be sufficiently stark to provoke some prospective participants to eschew the closest group in favor of a geographically inconvenient alternative. For example, an organizer for the March for Science Austin reported:

[I]t didn't really seem like I was going to be able to get to DC right around the beginning of the semester, and the Stand up for Science event on my campus, while technically a satellite march, seemed to have some influences that I didn't agree with ... I figured if I was, umm, going all the way to Austin, I may as well make sure it was something I wanted to be a part in.

This interviewee joined and helped to organize a satellite group located hours away because of dissatisfaction with the fact that the local satellite group was focused too 
much on public health and improving trust in biomedical resources, rather than encompassing broader issues such as climate change or general esteem for science.

The Women's March had a strong national presence, but many individual satellite groups were very well organized and developed their own values and goals very independently, with only the loosest of coordination with the national group. DWI groups were the most grassroots in nature, yet shared information, practices, and institutions horizontally to great effect, illustrating the strength of the network in developing something to a large scale, despite the fact that some satellite demonstrations did not even occur on the same date as the national event. For example, while most demonstrations took place on February 16, 2017, Milwaukee had its demonstrations three days prior. Organizers of individual satellite marches and walk-outs emphasized the importance of solidarity in objectives, as much as in actions, throughout interviews. One organizer explained groupto-group interaction, as a process of assimilation that did not involve any top-down pressure or aggregation, but rather depended on coordinated interactions between many individuals:

Yeah, well we do things a lot, but also with other lists and groups, that I follow, a lot. One of them, it's called ... I'm going to look it up real quick, hold on ... anyways, it's One Texas Resistance, that's close to the border, you know what I mean? People here feel pressure, people here connect, but to connect to people there, through social media, is powerful. Share words, show solidarity, share pictures ... it's a good thing ... And the fact that I have an education and the knowledge to spread the word, that's what I'm trying to make a difference on, get it all out there. The fact that I have this information, I want to spread it to more people.

Satellite groups often wanted to learn from one another and leverage national numbers to attract attention to their causes, while serving their own specific communities.

Tensions and dissension about goals and objectives sometimes led satellite groups to differentiate themselves from the national group. Even provocations by outsiders might lead to productive discussions about how the scope of a group's objectives could be narrowed in a way that was acceptable to at least some detractors. For example, a post stating "Immigrants are great! But illegal aliens should not be here. I wish the two wouldn't be used to mean the same thing" triggered a discussion that led one local movement to focus on demands for immigration reform, consideration for families, and respectful dialogue, rather than including calls for amnesty. This approach made that satellite group a relative outlier within the larger movement.

Even the language used to frame problems and objectives was sometimes contested. For example, posts in various DWI Facebook groups related to whether the objectives, and underlying problems, were about illegal or undocumented individuals, "aliens" or "criminals." Extreme objectors posted things like: 
Ok so you don't like "illegal”. We will just start calling them what they really are. Criminals..I am a "legal" US citizen, but if I break the laws in our country I am .. wait for it ... A Criminal

In response to these debates, very different agreements and discussions evolved within different local groups across the country as outside stakeholders contested the legitimacy of the groups and groups responded.

Other provocations re-shaped demonstrations. For example:

If all of the undocumented students don't show up to school on one day

Then you've got a real good list of all the undocumented students to be reported to ICE or whatever

Doesn't it seem counterintuitive saying "hey I'm an illegal" during this presidency?

In response to this post, this group designed a more inclusive demonstration, with friends and supporters obfuscating the status of their undocumented classmates.

\section{$5 \cdot 5$ GOVERNANCE}

\subsubsection{Institutions}

Polycentric institutional arrangements defined governance within these cases. Within legal and regulatory institutions regarding freedoms of association and expression, Facebook and other platforms, including EventBrite, Twitter, Slack, and Snapchat provide overarching infrastructure in which individual groups created their own institutions, which alternately abide, work around, or contradict the constraints placed upon them within the nested structure.

Governance mechanisms within these movements were distinctive, yet membership rules, resource contribution, and knowledge sharing expectations had many similarities. For example, very broadly, the membership norm was to have low barriers to entry, without expectations to contribute information or actively organize. Yet there was a clear norm that attendees should publicize and share event details and information resources that were generated by the more active participants.

Across all three movements, there was little explicit discussion of rules within Facebook groups or on other public platforms. Nonetheless, normative expectations about civility in dialogue were often specified (e.g. "yes, i'm sorry it is a little condescending, please edit that out if you could or i'll delete it when i get back :) your heart is in the right place but no human is superior than another human"). Norms of authority were reflected in requests to provide references or sources in order to back up claims (e.g. "I didn't see that. Where did you read that? I'm not saying it isn't true, but") or assist other members (e.g. "can you share those details") were ubiquitous. 
The logic, as well as the process, of decision-making in these groups was often non-transparent, despite the groups' ostensibly open nature. For groups at the national level, as well as satellites in large cities such as NYC or Seattle, the lack of transparency sometimes stemmed from the fact that such large groups became dysfunctional when too many people were involved in organizing and decisionmaking. For smaller satellites, lack of transparency often emerged simply because one or two individuals alone acted as the driving forces of these groups. Furthermore, because much of the decision-making process in these groups occurred off of the public Facebook groups, the best sense of how governance was handled comes from the Facebook group FAQs and from interviews. Moderation of discussion in the Facebook groups was an apparent form of governance. And, of course, governance is also formalized in the technological infrastructure and configurations of platforms.

Informal norms and strategies, relative to how people interacted and what was acceptable information to share, were emerged in an ad hoc fashion and by example, rather than from thoughtful strategic planning. Thus, there were many levels of institutionalization and few internal objections to governance designs for these groups. Overall, responses to our survey suggest that the governance was perceived to be legitimate, though there was sometimes disagreement about particular choices.

Privacy, as governance of personal information flow, was often not discussed publicly, even when privacy was a primary focus of many FAQs, discussions amongst organizers, and provided the logic behind numerous decisions. It is notable that interviewees cited their movements' privacy values very confidently, even when they had not discussed them explicitly with others in the group; "I'm not sure ... I ... as we have talked, this idea has come to me, but it's not something we decided on ... I think we are informal and local, loose connections to other immigrant groups, because it provides privacy and keeps people safe."

Some specific rules-in-use about personal information were discussed prominently, however, including those against oversharing in light of threats associated with disclosure outside of the group (e.g. "Everybody: Don't share immigration statuses. Privacy settings don't hide comments. It's a public group”). Questions about appropriateness were common in the Facebook postings, for example "should we really post pictures? there is no expectation of privacy at a public event" (Facebook post). Beyond privacy-related rules-in-use reflected in the posted discussions, heavy moderation was easily evident on the public Facebook pages of some groups. For example, of 4,352 posts associated with the seven DWI groups that we studied, only 3,946 still have readable text, indicating that 406 have been deleted. Timestamp and post ID, without a post, are downloadable metadata through the API, and in some cases it is possible to infer what the post may have discussed, by looking at responses that are still visible on the page. This illustrates both a privacy threat and an instance in which polycentric governance is competitive, rather than 
complimentary. While many of the deletions by organizers moderating these pages were intended to remove inappropriate flows of personal information that had been shared, as enforcement of rules governing DWI groups, overarching platform level governance by Facebook undermined this effort, to an extent, by maintaining context and metadata.

There were very real concerns expressed by movement members about surveillance and about what Facebook would do with the data it had amassed about individual participants and groups overall. While this concern was most prominently expressed in relation to DWI groups, members of groups across all three movements echoed the concern. As one organizer explained:

I think Facebook makes a lot of decisions that don't make people happy, that may not ... well affect people, about their privacy, but most of that is not special to us. What is different, what is important and maybe a problem, is how Facebook works with law enforcement, with ICE. I don't know, really, what happens ... I don't think they have to tell us, but people talk and people are afraid.

Many individuals, across all three movements, expressed doubts about the legitimacy of Facebook's role in making decisions about their groups' information. Furthermore, there was entrenched distrust that Facebook would adhere to what was stated in policies; "We agree to Facebook when we use it, but they don't always do what they say and it changes" (March for Science participant, survey response). Nonetheless, most felt it was necessary to sacrifice in order to benefit from Facebook's social capabilities. They did not see any alternative.

While rules and expectations about conduct within groups were often implicit, aside from rules about sharing information and admonitions to mind norms about civil conversations, there was active enforcement of content and civility standards through moderation. These practices were frustrating to some good-faith participants, who did not understand the implicit expectations, yet faced explicit consequences in moderation. Moderation more often manifested when group organizers simply deleted posts that didn't reflect community standards but, occasionally, organizers would articulate expectations and give participants an opportunity to edit their posts, with deletion serving as a last resort. Beyond censorship, there were no other real consequences or sanctions for violations and conflicts between members or members and outsiders were resolved on an ad hoc basis or through excision by moderators, rather than through any formal or consistent procedure.

\subsubsection{Actors in Governance}

Actors involved in governance, regardless of movement or satellite group, were not always key stakeholder groups and did not include all members in any case. Yet interactions between groups and the permeability of boundaries were often relatively open, allowing for interested and committed individuals to be as involved as they 
wanted to. DWI groups were relatively the most different than other groups, in terms of having most key organizing roles filled by advocates and family members, rather than undocumented individuals themselves, as least in terms of how these groups documented and presented themselves to outsiders in order to protect impacted individuals' privacy. As one DWI organizer, for a student-led satellite group, explained:

There are a lot of immigrants within the community. Stamford, as a city, is made up of over $30 \%$ immigrants, or non-citizens, so really like a third of people here were born outside of the United States and so we were trying to show that. We were also trying to get rid of peoples' fear, particularly those of students, so that ... there was a lot of confusion.

The organizers, in some cases relatives of immigrants, were themselves simply "civically engaged" and wanted to ensure that their families and classmates were welcome in the community. Other DWI groups were organized by DREAMERS, as well as friends and relatives, and made decisions independent of, yet representing, the impacted communities. In contrast, most Women's Marches were organized by women.

March for Science decision-makers often included a combination of scientists, science educators, and STEM students, along with other STEM advocates. As one March for Science organizer explained:

it seemed that a lot of science faculty were eager to attend, and some of them to speak or do demos for kids or something, but they didn't have time or experience to organize. Also, some of them were concerned about whether that was really professional for them. For me, I work in communications for the university, I didn't have the same concerns and I had the time. It was important to me, in terms of my kids and a world I wanted to live in. I started our local movement, but had a lot of really great students, from biology and chemistry, even engineering, who wanted to help and did a great job.

This movement was in many cases more collaborative.

Actors involved in governance often expressed their desire to be inclusive, yet also their fears of being influenced by those with contrary values, particularly given concurrent activism by "white supremacists and Neo-Nazis." Boundaries were open, but actively policed, in order to avoid co-option. It was also particularly interesting to see who the groups, or the interacting public, attempted to exclude, given that they were working within open, public Facebook groups. Stakeholder groups wanted to engage the public, but not necessarily everyone in their own networks. As one organizer of a DWI satellite group responded, when asked about establishing boundaries:

Well, sort of. We do not want our employers involved. We do not share with police or immigration officers ... we prefer those we fear not to be too close, though I think they say keep enemies close ... I do not think they are all enemies, but there is fear. 
In this sense, members within groups often leveraged their control, as enabled by Facebook, over who specific posts would be shared with, based on whether they were friends and family, or colleagues, driven by concerns about repercussions from nested oversight.

Decision-makers in all groups were often those who felt personally invested and frustrated with current politics, becoming involved through social media and interpersonal interactions and relationships. Actors who engaged in organizing in most cases were in small, close knit groups, yet at the national level and in some of the largest satellites, large groups coordinated. Smaller satellites were often organized by 1 to 25 individuals, in contrast to the roughly 1000-member group that organized the national Women's March. Overall, decision-makers were generally perceived to be legitimate in organizing, though criticism remained about the non-representative nature of many of the Women's March groups, in particular.

\subsection{PATTERNS AND OUTCOMES}

The public support, across all three movements, illustrated the relative successes, in terms of shaping debate, yet varied dramatically in terms of the consequences. While the March for Science supporters and organizers faced relatively little opposition, the Women's March has faced audible criticism and the DWI movement has documented numerous repercussions, documented within media coverage in the form of the number of individuals who lost their jobs for failing to report to work during the demonstrations.

Benefits to members and others are relatively difficult to ascertain at this point in time, though many have discussed attitudinal changes relative to gender discrimination, manifesting in \#MeToo and accountability for aggressors and perpetrators of sexual harassment and assault as being tied to the Women's March movement. However, the attention gained by all three movements is important, as they demonstrated more widespread support than anticipated. Their creative outputs, in the forms of informative campaigns and knowledge resources about their positions, also persist and are being broadly disseminated, establishing social interactions from both the resources themselves and sustained from interactions at demonstrations. Many of the interactions that emerge from the communities' activities are perceived to be a wonderful benefit toward larger community building by active participants. As one Women's March satellite organizer explained, "I showed up to the meeting alone. I met some great ladies, most of whom I'm still in contact with .... It's wonderful."

Perceptions of success by many members, stakeholders, and the media, were contested, however, by ideological opposition, particularly around the legitimacy of the groups as grassroots, rather than mouthpieces of existing organizations, like Planned Parenthood, and in accepting the attendance numbers as fact. 


\section{$5 \cdot 7$ IMPLICATIONS}

\subsubsection{Privacy Values in Public Facebook Groups}

Despite the obvious impact of privacy values and practices on political demonstrations and movements, the most innovative applications of privacy as governance within these communities shaped the use of public Facebook groups, often in ways specific to ideological or sensitive uses of this technology. Four distinct privacy values emerge, shaping public Facebook groups as commons arrangements: privacy through obscurity; privacy and chilling effects; privacy through autonomy; and participatory privacy.

Privacy was, in many instances, sought through obscurity. Various groups and individuals emphasized the anonymity provided to them by the crowds in demonstrations and the relative safety they felt within the sheer number of supporters, often beyond the expectations of organizers and the media in advance of events. Governance structures around photographs and publicity particularly emphasized this preference, minimizing the ability to single out participants publicly, to the best of their abilities. Large groups also emphasized privacy through obscurity in their configurations of Facebook groups and common patterns of engagement, allowing public numbers, without identities, within RSVP design and through the use of "following" rather than "joining" mechanisms.

Privacy concerns also generated chilling effects, regarding participation patterns. This was closely coupled to fear of repercussions, rather than inappropriate flows alone, with many informants for this research conflating these two problems. Comparing immigration advocacy groups to the Women's March, there were differences in not documenting or "lurking" participation for the immigrants" groups, in comparison to subtle behavioral shifts, or deleting documentation, for the women's groups. While merely symptoms of the more primary surveillance harms and possible repercussions, they represent distinct burdens and tradeoffs surrounding participation (Brennan-Marquez \& Susser, work in progress). In this sense, privacy dramatically shaped participation, in addition to resources and governance.

Participatory privacy - including anonymous and pseudonymous participation, as well as non-identifiable participation in a crowd - presented a related set of strategies yet was independent of chilling effects and drew on diversity of modes of interaction. Specifically, the use of multiple platforms and institutional designs that obfuscated identification of sensitive attributes associated with stakeholders in the communities provided a means of participatory privacy, whether though encrypted channels for organization of immigration groups or proxy participants, as well as the use of existing organizational infrastructure, by March for Science groups, to protect junior scientists' careers. Central to Facebook specifically, choices made by individual participants to utilize the least publicly transparent modes of interaction with public groups illustrate 
nuance to participatory privacy. Following, rather than joining, a group allowed individuals to include information from the groups in their newsfeeds and notifications, without anyone else knowing they were followers. Similarly, liking a group without joining it supported sharing the interest only with friends, rather than with the general public.

Privacy was also attained by many through autonomy. A commons arrangement, in which individuals and collectives had control over flows, rather than accepting other decision-makers' choices around appropriateness or imposed flows, provided acceptable outcomes regarding personal information. Groups made choices to use multiple channels and delete contact resources, in order to contradict default practices or designs of platforms and prevent privacy harms imposed by platforms, law enforcement, or political opposition. These creative choices and work-arounds reflected a desire to overcome the structural and institutional efforts by online platforms, like Facebook, to undermine social norms about appropriate information flows (e.g. Strandburg, 2004, 2006) and were relatively successful at providing privacy to participants and stakeholders.

\subsubsection{Commons Governance for Grassroots Political Organizing}

The GKC provided a useful lens through which to explore how grassroots political organizing in public online spaces functions through commons governance, including privacy as governance. Not only were numerous norms and strategies revealed, as evidence of dependence on lower levels of institutionalization in complex and diverse contexts, but also the polycentric nature of governance arrangements was made visible.

Specifically, not only did individual movements have unique needs, which generated arrangement patterns, but individual groups illustrated creative ways of interacting with platforms like Facebook in their efforts to appropriately structure their communities. Differences in choices about platforms, as well as what arrangements of tools and configurations within those platforms, illustrated experimentation and context specificity, as well as distinct limitations of Facebook. While Facebook allows groups to control events, those created by individuals cannot be shared with other accounts, from an administrative standpoint, leading to inconveniences, as well as lack of functionality, for example, depending on the scope and development patterns for each group. Another example of a flaw for organizing related to what groups had access to, which varied by scope; larger groups did not have access to full lists of respondents to verify against EventBrite RSVPs, though Facebook has access to who might attend. Furthermore, many unique arrangements were designed to protect privacy, through the use of less public channels.

\subsubsection{Emerging Best Practices}

While the scale and frame of this study do not lend themselves toward best generalizable principles for online organizing, a number of privacy practices can be 
identified from these groups as emerging best practices, reflecting a grounded approach toward description, rather than prescription. Specific privacy institutions are shared within and across movements, with respect to how to handle personally identifiable stories, contact information, event photographs, and discussion moderation.

First, and most broadly accepted, it appears to be a key to success to use multiple platforms, particularly for predicting turnout through RSVP functions and in generating and protecting email lists or other contact information. This allows groups to reach more diverse communities with shared interests, as well as to triangulate. While groups had different expectations around what to do with those forms of information, it was considered best practice to have multiple platforms and not entrust everything to a single platform.

Second, photographs should be archived off of public platforms, regardless of whether they are deemed appropriate to also be hosted on commercial public platforms. Private servers, rather than cloud services, were more often trusted, though some did depend on secure cloud back up. Many groups also backed up contact lists, though there was not a clear consensus on how to do this, and notable exceptions actually deleted all of this information, as well.

Third, in organizing around contentious political issues within public online spaces, moderation has been deemed absolutely critical, even if the extent of moderation and the underlying rationales are different. While some groups were concerned about removing hate speech or fake information, others were concerned about detraction from their carefully constructed messages; whatever the reason, some control over the content is important in pursuing specific goals and maintain civil spaces.

Fourth, efforts were made in diverse groups to protect the personal stories and prevent identifiability of vulnerable members. Even though scientists perceived as public intellectuals were encouraged to disclose personal stories, junior scientists were protected in ways that were similar to individuals' immigration statuses and women in vulnerable situations, often associated with sexual harassment or domestic violence.

\section{Author note}

This chapter is derived in part from an article published in Information, Communication \& Society 2019, copyright Taylor \& Francis, available online: www.tandfonline.com/10.1080/1369118X.2019.1668458

\section{References}

Acquisti, Alessandro and Ralph Gross. "Imagined Communities: Awareness, Information Sharing, and Privacy on the Facebook." In Danezis G. and Golle P. eds., International Workshop on Privacy Enhancing Technologies, Lecture 
Notes in Computer Science, vol. 4258. Berlin, Heidelberg: Springer, 2006, 36-58. https://doi.org/10.1007/11957454-3

Blitzer, Jonathan. “After an Immigration Raid, a City's Students Vanish.” The New Yorker (2017), March 23, www.newyorker.com/news/news-desk/after-animmigration-raid-a-citys-students-vanish

Boothroyd, Sydney, Rachelle Bowen, Alicia Cattermole, Kenda Chang-Swanson, Hanna Daltrop, Sasha Dwyer, Anna Gunn et al. “(Re) producing Feminine Bodies: Emergent Spaces through Contestation in the Women's March on Washington." Gender, Place \& Culture 24, no. 5 (2017): 711-721.

Brennan-Marquez, Kiel and Daniel Susser. Privacy and Chilling Effects. (Work in progress).

Breuer, Anita. "The Role of Social Media in Mobilizing Political Protest." In Sayre, Edward A. and Tarik M. Yousef, eds. Young Generation Awakening: Economics, Society, and Policy on the Eve of the Arab Spring. New York: Oxford University Press, 2016, 110-131.

Ellison, Nicole B., Jessica Vitak, Charles Steinfield, Rebecca Gray, and Cliff Lampe. "Negotiating Privacy Concerns and Social Capital Needs in a Social Media Environment.” In Trepte, Sabine and Reinecke, Leonard, eds., Privacy Online, Berlin, Heidelberg: Springer, 2011, 19-32.

Fisher, Dana R., Dawn M. Dow, and Rashawn Ray. "Intersectionality Takes it to the Streets: Mobilizing Across Diverse Interests for the Women's March.” Science Advances 3, no. 9 (2017): eaao1390.

Frischmann, Brett M., Michael J. Madison, and Katherine J. Strandburg, eds. Governing Knowledge Commons. New York: Oxford University Press, 2014. González-Bailón, Sandra and Ning Wang. "Networked Discontent: The Anatomy of Protest Campaigns in Social Media." Social Networks 44 (2016): 95-104.

boyd, danah and Eszter Hargittai. "Facebook Privacy Settings: Who Cares?." First Monday 15, no. 8 (2010). https://doi.org/10.5210/fm.v15i8.3086

Hamann, Edmund T. and Cara Morgenson. "Dispatches from Flyover Country: Four Appraisals of Impacts of Trump's Immigration Policy on Families, Schools, and Communities." Anthropology \& Education Quarterly 48, no. 4 (2017): 393-402.

Kaplan, Andreas M. and Michael Haenlein. "Users of the World, Unite! The Challenges and Opportunities of Social Media." Business Horizons 53, no. 1 (2010): 59-68.

Kitch, C. “'A Living Archive of Modern Protest': Memory-making in the Women's March.” Popular Communication 16, no. 2 (2018): 119-127.

Kocher, Austin. "The New Resistance: Immigrant Rights Mobilization in an Era of Trump." Journal of Latin American Geography 16, no. 2 (2017): 165-171.

Madison, Michael J., Brett M. Frischmann, and Katherine J. Strandburg. "Constructing Commons in the Cultural Environment." Comell L. Rev. 95 (2009): 657 .

Marwick, Alice E. and Danah boyd. "Networked Privacy: How Teenagers Negotiate Context in Social Media." New Media ๒ Society 16, no. 7 (2014): 1051-1067. 
Milman, Oliver. "March for Science Puts Earth Day Focus on Global Opposition to Trump." The Guardian (April 22, 2017), www.theguardian.com/environment/ 2017/apr/22/march-for-science-earth-day-climate-change-trump

Moss, Pamela and Avril Maddrell. "Emergent and Divergent Spaces in the Women's March: The Challenges of Intersectionality and Inclusion." Gender, Place \& Culture 24, no. 5 (2017): 613-620.

Nam, Taewoo. "Dual Effects of the Internet on Political Activism: Reinforcing and Mobilizing." Government Information Quarterly 29 (2012): S9o-S97.

Nissenbaum, Helen. Privacy in Context: Technology, Policy, and the Integrity of Social Life. Stanford, CA: Stanford University Press, zoog.

Ostrom, Elinor. "Background on the Institutional Analysis and Development Framework." Policy Studies Journal 39, no. 1 (2011): 7-27.

Reardon, Sara, Nicky Phillips, Alison Abbott, Barbara Casassus, Ewen Callaway, Alexandra Witze, Corie Lok, and Emiliano Rodriguez Mega. "What Happened at March for Science Events Around the World." Nature News 544, no. 7651 (2017): 404 .

Robbins, Liz and Annie Correal. "On a 'Day Without Immigrants' Workers Show Their Presence by Staying Home." The New York Times (February 16, 2017). www.nytimes.com/2017/o2/16/nyregion/day-without-immigrants-boycott-trumppolicy.html

Rose-Redwood, CindyAnn and Reuben Rose-Redwood. "It Definitely Felt Very White': Race, Gender, and the Performative Politics of Assembly at the Women's March in Victoria, British Columbia." Gender, Place \& Culture 24, no. 5 (2017): 645-654.

Sanfilippo, Madelyn Rose and Katherine J. Strandburg. "Privacy Governing Knowledge in Public Facebook Groups for Political Activism." Information, Communication \& Society (2019): 1-18. 10.1080/1369118X.2019.1668458

Sanfilippo, M., Frischmann, B., and Strandburg, K. "Privacy as Commons: Case Evaluation Through the Governing Knowledge Commons Framework." Journal of Information Policy 8 (2018): 116-166.

Selepak, Andrew G. "Exploring Anti-Science Attitudes among Political and Christian Conservatives through an Examination of American Universities on Twitter." Cogent Social Sciences 4, no. 1 (2018): 1462134.

Stacheli, Lynn A. "Publicity, Privacy, and Women's Political Action." Environment and Planning D: Society and Space 14, no. 5 (1996): 6o1-619.

Stein, Perry. "Day Without Immigrants' Aims to Show Importance of Migrants." The Washington Post (February 16, 2017).

Strandburg, Katherine J. "Privacy, Rationality, and Temptation: A Theory of Willpower Norms." Rutgers L. Rev. 57 (2004): 1235.

Strandburg, Katherine J. "Social Norms, Self Control, and Privacy in the Online World." In Katherine J. Strandburg and Daniela Stan Raicu, eds., Privacy and Technologies of Identity, Boston, MA: Springer 2006, 31-53.

Wallace, Tim and Alicia Parlapiano. "Crowd Scientists Say Women's March in Washington had 3 Times as Many People as Trump’s Inauguration." New York 
Times 22 (2017). www.nytimes.com/interactive/2017/01/22/us/politics/womensmarch-trump-crowd-estimates.html

Weible, Christopher M., Paul A. Sabatier, Hank C. Jenkins-Smith, Daniel Nohrstedt, Adam Douglas Henry, and Peter DeLeon. "A Quarter Century of the Advocacy Coalition Framework: An Introduction to the Special Issue." Policy Studies Journal 39, no. 3 (2011): 349-360. 